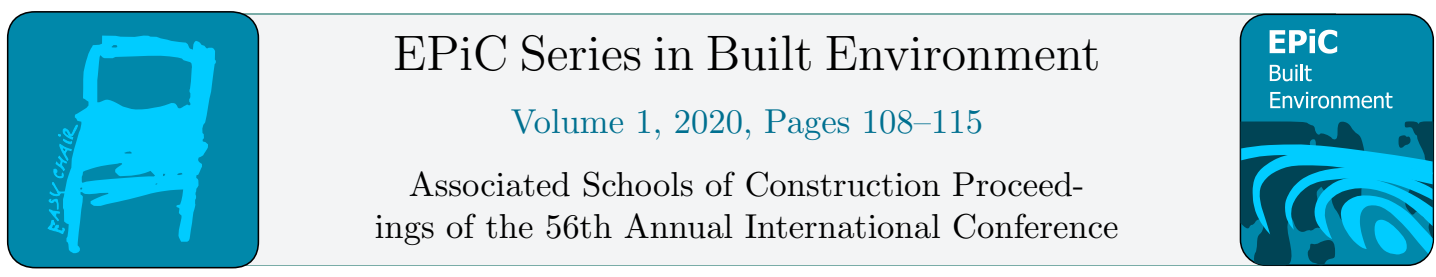

\title{
Effects of Virtual Reality on Student Learning in Materials and Methods Course
}

\author{
Jason Lucas, $\mathrm{PhD}^{1,2}$ and Dhaval Gajjar, $\mathrm{PhD}^{1}$ \\ ${ }^{1}$ Clemson University, Clemson SC, USA \\ 2jlucas2@clemson.edu
}

\begin{abstract}
Virtual Reality (VR) offers a method of active and interactive learning. In this research, a VR-based simulated environment is used to help students gain an understanding in the sequencing of construction activities within an undergraduate materials and methods course. The VR simulation was developed to augment traditional classroom learning methods. The sequencing simulation allows students to freely navigate through the simulation and walk through the steps of the construction for a small wood frame structure. The simulation was developed for both immersive and nonimmersive desktop-based simulations. During early studies, it was found that students were receptive of the technology and perceived a benefit in understanding spatial qualities as well as components of assembly but actual effects of learning were not identified. The current study explores the actual effects of student learning when incorporating simulation into the coursework. This paper discusses the comparison of students learning from a control group where the simulation was not used to the learning of a group who utilized the desktop-based simulation in addition to traditional classroom methods.
\end{abstract}

\section{Introduction}

Virtual Reality (VR) is a computer simulated environment that allows for user interactions in a virtual world. When properly developed, VR can provide students with an active learning environment (Sala, 2016). The active nature of VR allows for learning that is more efficient, improves recall of information, and provides an experiential learning tool to transfer perceived knowledge to practice (Maghool et al, 2018). 3D environments can also increase learners' engagement and motivation in the learning tasks while offering a more enjoyable experience than traditional methods (Winn et al., 2002; Youngblut, 1998). Additionally, evidence suggests that freely navigating around a virtual environment stimulates brain activity by creating a higher level of cognitive encoding within working memory which correlates to greater success with cognitive retrieval (Jaiswal et al, 2010). VR has been explored through many educational domains, and has proven a useful augmentation to traditional learning when time, 
inaccessibility of the physical even, safety due to dangerous situations or other ethical concerns are barriers to physical participation in the event (Freina \& Ott, 2015).

For construction management, an interactive simulation was developed to help students with problem solving and critical thinking related to problems of risk management (Pariafsai, 2016). Sampaio et.al. (2010) identified the impact on student understanding of construction methods and assemblies in relation to bridge models in civil engineering education when utilizing a model that can be easily deconstructed within a virtual environment. Construction safety is another arena where 3D simulation and virtual reality have been explored to test human behavior in unsafe work scenarios when training new employees (Hilfert et.al., 2016). Additionally, safety information was incorporated through mobile-based virtual simulations into a construction materials classroom (Pedro et.al., 2016). Within design, case studies identified that immersive simulated design reviews in healthcare showed benefits of greater understanding of spatial conditions by the future occupants of the facility (Lin, 2018).

\subsection{Current Study}

Makransky and Petersen (2019) found that using virtual simulations can increase the learners' motivation, self-efficacy, and performance on learning outcomes. Additionally, simulations are effective at developing and testing students' knowledge level (Merchant et.al, 2014). Because of the benefits documented in literature and similar restrictions within the physical learning environment as defined by (Freina \& Ott, 2015), VR is being explored for demonstrating sequencing activities in the Materials and Methods of Construction classroom at the undergraduate level (Lucas, 2019). The simulation was created using Unity to program the sequencing environment. The model of the wood framed structure was developed using Sketch-Up (Fig. 1). The desktop simulation is controlled by utilizing the mouse and keyboard to navigate through the environment much like a first person video game. Additionally trigger keys were used to advance steps of the sequence and alternatively move backward in the simulation. Notations were included to describe to the user what is happening during each step.

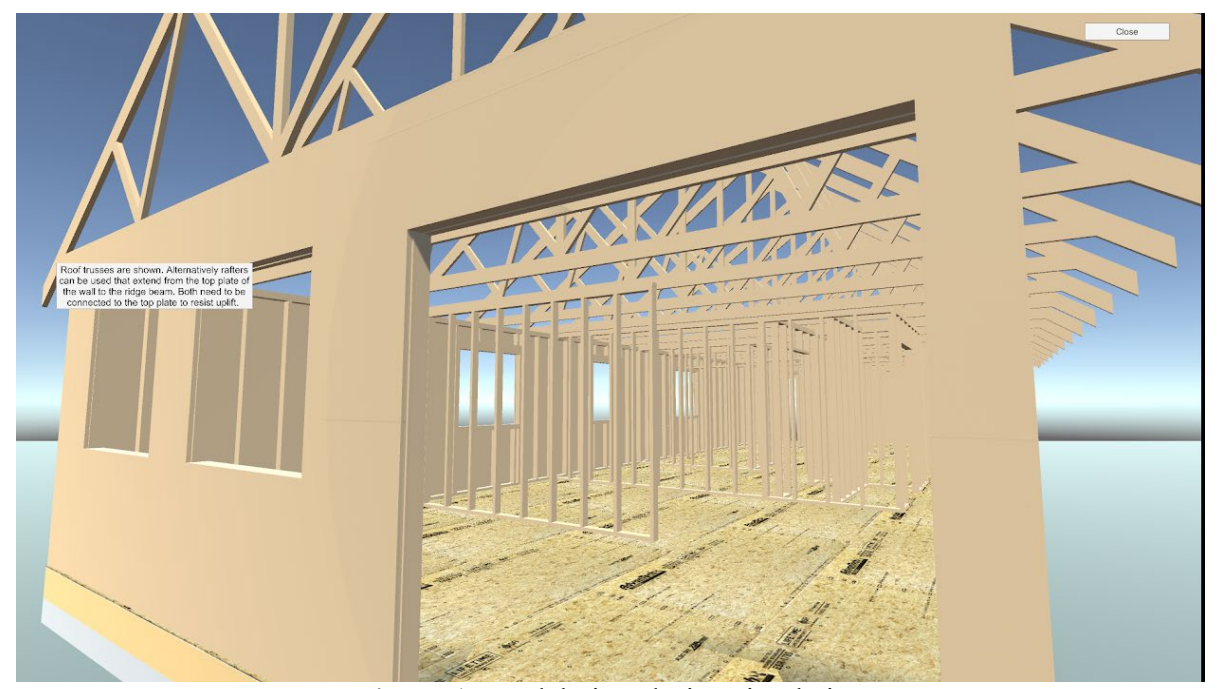

Figure 1: Model view during simulation

Early findings of preliminary studies showed promise with student perception of the technology being useful for augmenting the classroom in terms of understanding sequences of construction assemblies (Lucas, 2019) as well as providing a better perception of the understanding of space (Lucas, 
2018). This paper explores the actual learning of the student when utilizing the simulation versus traditional classroom methods of education.

\section{Research Methodology}

The research methodology for this study is outlined in Fig. 2 below. A common assessment tool was developed and utilized to compare the performance of two groups.

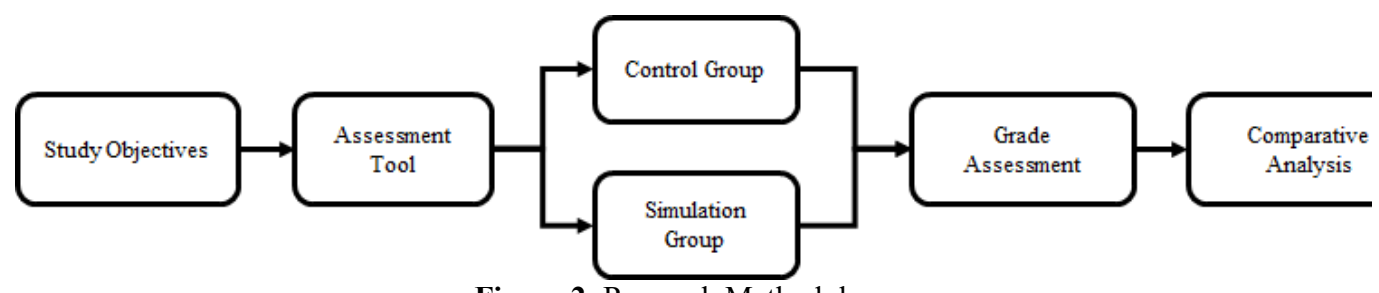

Figure 2: Research Methodology

\subsection{Study Objectives}

The main objective of this study is to compare the actual learning of the students in a Materials \& Methods of Construction course when utilizing traditional classroom methods of education versus simulation model. To allow for a large enough group of participants for the comparison, the study was conducted over two semesters. The teaching methods and materials used for classroom instruction during the two semesters were identical. The first semester student group served as a control group for the study which included traditional classroom teaching and did not have access to the simulation. The second semester student group included the same traditional classroom teaching as the control with the addition of having access to the simulation in the form of desktop / immersive simulation.

\subsection{Assessment Tool}

The outcomes for the course are at the level of "Understand". Since the course is a foundational level course, the students are expected to be able to recognize and identify aspects of materials and methods. In order to evaluate the students' understanding and retention of the material, an assessment tool was developed. The assessment tool was provided as an assignment to the students for each semester after covering the relevant topics for this study and included three key aspects to measure students' understanding of the material:

1. Open response - This assessment was used to test a higher level of understanding by examining the students' ability to recall the information that was presented to them without providing context to aid in the recognition of what was required. The students were asked to write the steps, in order, for completing a wood frame structure from digging the foundation through completion of finishes with the assumption there was a basement foundation.

2. Sequence Order - This assessment tests a lower level of understanding by requiring the students to recognize information within a given context. The students were asked to put the predetermined steps (total of 23 steps) into the correct sequence for building a typical one story wood framed structure.

3. True / False - To test the students' overall comprehension of the material and other details that were presented within the classroom and simulation, the students were asked to 
complete Twenty-five (25) true or false questions on various aspects regarding the wood frame structure building.

4. Perception Survey - The students who participated in the simulation group were also asked a series of perception questions about the simulation and use of simulations for education.

\subsection{Participants (Control Group \& Simulation Group)}

Student groups from Materials \& Methods class for two consecutive semesters were deemed appropriate for the study. A total of thirty eight (38) students were enrolled in the first semester as a control group. Out of the thirty eight students, a total of thirty six (36) students ( $94.7 \%$ response rate) completed the assessment. A total of thirty-nine (39) students were enrolled in the second semester which included traditional classroom teaching with the addition of the simulation tool. Out of the thirty eight (38) students, a total of thirty seven (37) students $(97.4 \% \%$ response rate) completed the assessment and thirty-one (31) students (81.5\% response rate) completed the perception survey.

\subsection{Grade Assessment}

Open response and sequence order question was analyzed by calculating the percentage of the total number of steps that were listed in the correct sequence for each student. True / False question was analyzed by calculating the total number of correct responses for each student. Lastly, a perception survey was also given to the students who participated in the simulation groups.

The open response questions were coded into major steps. Reasonable interpretation was needed as there can be variations in the sequence as well as in how they are described. For instance, "locate and construction foundation" was one scoring category. Some students were very specific as to lay out batten boards, dig a foundation, pour foundation walls, etc. If a student listed several steps of the scoring category they still only received one point for that category. In total twelve categories were identified for scoring in the open response.

The items for the sequence order were provided to the students who then had to put them in order. Again, reasonable interpretation to appropriate variations to the order was needed when scoring the responses. The steps were more detailed than the expected scoring categories of the first open response question in the hopes to gauge a deeper understanding of the details of the construction sequence.

True/False questions were developed to test the students' comprehension of the details of wood frame construction. The questions were designed to promote a more critical thought of the sequence and gauge the students' understanding of why certain components are used and which activities are required precedent activities to each other. These were used to test both the students understanding of the sequence of construction as well as other details related to the components of assemblies that were included in the simulation and course content.

\section{Comparison Analysis}

Each student group from both semesters completed the same relevant assessment for the course and the results of the assessments were then compared to identify the effects of the simulations on learning. Table 1 outlines the results of the assessment for the control student group.

\begin{tabular}{lccccc}
\hline Assessment & $\begin{array}{c}\text { Number of } \\
\text { Students }\end{array}$ & $\begin{array}{c}\text { Total } \\
\text { possible } \\
\text { points }\end{array}$ & $\begin{array}{c}\text { Total correct } \\
\text { points }\end{array}$ & $\begin{array}{c}\text { Percent } \\
\text { Correct }\end{array}$ & $\begin{array}{c}\text { Individual } \\
\text { Response } \\
\text { Range }\end{array}$ \\
\hline 1. Open Response & 36 & 432 & 254 & $58.8 \%$ & $33.3 \%-91.7 \%$
\end{tabular}




\begin{tabular}{llllcc}
$\begin{array}{c}\text { 2. Sequence } \\
\text { Order }\end{array}$ & 36 & 807 & 474 & $58.8 \%$ & $22.7 \%-95.5 \%$ \\
3. True / False & 36 & 775 & 472 & $60.9 \%$ & $48 \%-78 \%$ \\
\hline
\end{tabular}

Table 1: Control Group Results

A total of 36 students completed the assignment for the first semester control group. A cumulative total number of points possible and a cumulative total number of correct answer points for all students as a control group was calculated for the open response, sequence order and true / false questions. As a control group, $58.8 \%$ of the answers were correct for open responses and sequence order whereas $60.9 \%$ of the answers were correct for true / false questions.

A total of 38 students completed the assignment for the second semester intervention group. One student did not respond to the open response and sequence order but did respond to the true / false questions. Table 2 outlines the results of the assessment for the group who participated in the simulation.

\begin{tabular}{lccccc}
\hline Assessment & $\begin{array}{c}\text { Number of } \\
\text { Students }\end{array}$ & $\begin{array}{c}\text { Total possible } \\
\text { points }\end{array}$ & $\begin{array}{c}\text { Total correct } \\
\text { points }\end{array}$ & $\begin{array}{c}\text { Percent } \\
\text { Correct }\end{array}$ & $\begin{array}{c}\text { Individual } \\
\text { Response } \\
\text { Range }\end{array}$ \\
\hline 1. Open Response & 37 & 444 & 246 & $55.4 \%$ & $25 \%-91.7 \%$ \\
2. Sequence Order & 37 & 800 & 597 & $74.6 \%$ & $47.8 \%-95.7 \%$ \\
3. True / False & 38 & 950 & 563 & $59.3 \%$ & $40 \%-76 \%$ \\
\hline
\end{tabular}

Table 2: Simulation Group Results

For the simulation group, an overall $55.4 \%$ of the answers were correct for the open responses with a range of $25 \%-91.7 \%$. The group performed better with a $74.6 \%$ correct for the sequencing order question. A comparison of the results of the two groups is presented in table 3.

\begin{tabular}{cccc}
\hline Assessment & Control Group & Simulation Group & Percent Difference \\
\hline 1. Open Response & $58.8 \%$ & $55.4 \%$ & $-3.4 \%$ \\
2. Sequence Order & $58.8 \%$ & $74.6 \%$ & $+15.8 \%$ \\
3. True / False & $60.4 \%$ & $59.3 \%$ & $-1.1 \%$ \\
\hline
\end{tabular}

Table 3: Comparison Analysis

A t-test was performed between control group and simulation group to compare the student outcomes for three assessments. Upon performing t-test for open response assessment and true / false assessment, the results were found to be statistically insignificant with a p-value of 0.24 and 0.28 respectively at the $95 \%$ confidence level. Upon performing t-test for sequence order assessment, the results were found to be statistically significant with a p-value of 0.0000051 at the $95 \%$ confidence level. This shows that both the control group and simulation group performed similarly in terms of the open response and true / false assessment. There was significant improvement of the simulation group in terms of the sequence order assessment. Fig. 3 shows the scores, sorted from lowest to highest, plotted for each of the groups. 


\section{Assessment \#2: Sequence Order}

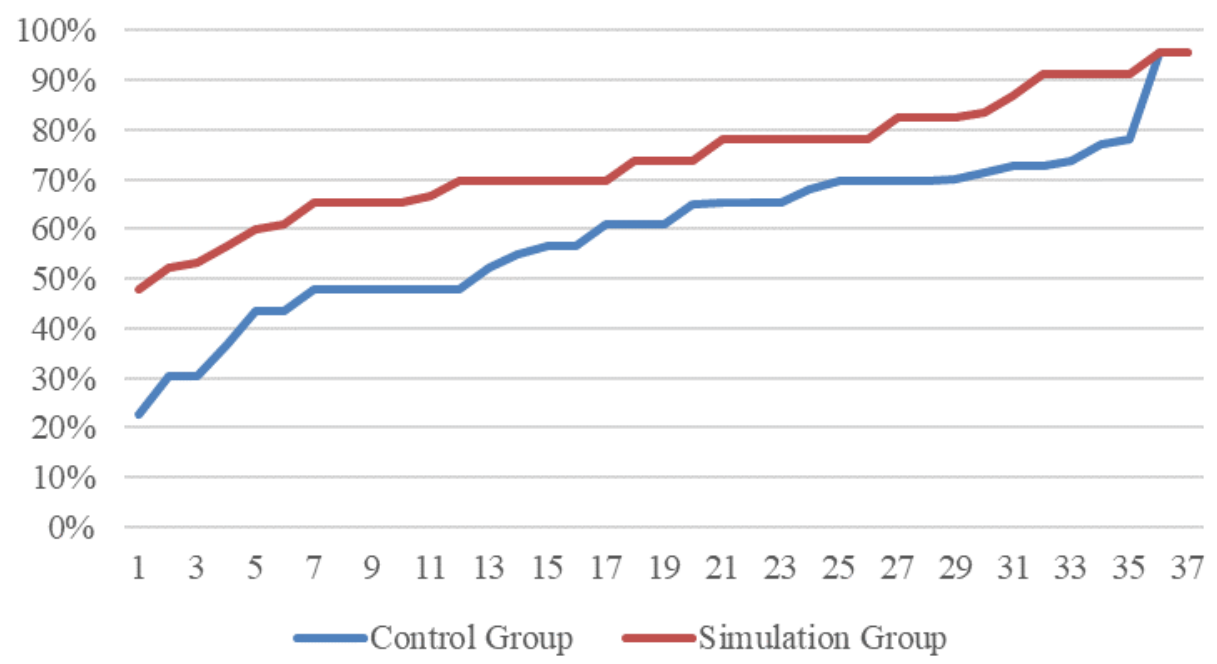

Figure 3: Assessment \#2 Score Comparisons

Other observations that were not quantified by the designed assessment measure were:

1. Several of the submissions for the simulation group "open response" had very detailed statements of sequence order but only covered the first section of the assessment. The details were related to smaller steps of the wood framing process and then were too vague or less general in terms of finishes. The students may have misinterpreted the directions though they were asked to write out the steps from layout to completion of all finishes.

2. Some students expressed frustration in the second question where they had to put the steps in sequence. The issue was with the design of the assessment being a series of drop-down menus to put the steps in order. If a step was missed and an edit needed to be made a student would have to go through and modify all later steps. It was evident that several students stopped answering the question and moved on and did not complete the steps. These responses were removed from the analysis as to minimize difficulty with the assessment influencing the results.

\section{Perceptions of Simulation Use}

A perception survey was administered through Qualtrics to the simulation group. The survey included eighteen questions that documented basic demographics related to use of video games and familiarity with virtual simulations, perceptions of the wood-frame sequencing simulations, and perceptions of the use of VR simulations to augment the traditional classroom. In total, thirty-one (31) complete responses were received. Of those who responded, 29 (93.5\%) indicated to "never" or "not often" playing video games on a computer where the keyboard and mouse were used for navigation. Even with the minimal use similar video games $87 \%$ "strongly agreed" or "somewhat agreed" to the statement that the simulation was intuitive to navigate and that the simulation controls were easy to adapt to. 
Additionally, the students indicated that they perceived a benefit to the use of the simulation. $96.6 \%$ of the respondents indicated "strong agreement" or "somewhat agree" to the statement "using virtual reality increased my interest in the subject. Additionally, 93.3\% "strongly agreed" or "somewhat agreed" to the statement "Virtual Reality (VR) enhances my learning of the presented material".

\section{Conclusion}

This paper discusses the preliminary findings of a study that attempts to gauge the effects of virtual reality and 3D simulation on student learning in a materials and methods course. A virtual simulation was developed in previous research that created a sequencing simulator for wood frame construction. Two groups of students, over two semesters of the course were used for comparison in this study. The first semester was taught without the introduction of the simulation as a control group. The second semester included the introduction of the 3D simulation in a desktop simulation format. The students were assessed utilizing a three part tool to gauge their understanding of the content. The first assessment utilized an open response to identify the retention of material and the ability of the students to recall details of the construction process. The second assessment then provided detailed steps and required students to put those details in the correct order. Lastly, students were tested on a series of true / false comprehension questions.

The preliminary findings of the study show that for information recall and comprehension of the content questions there were no significant differences between the two groups. However, when provided the details, the students who utilized the simulation were able to put those details in a correct order with $15.8 \%$ more accuracy than that of the control group. For this study, the students were able to recognize the information and the simulation appears that it may have an impact on that recognition. However, when asked to recall the information (assessment 1) there was a slightly less level of accuracy $(-3.4 \%)$ compared to the control group. The simulation allowed for greater understanding at a lower level of comprehension in terms of recognizing steps of construction within a given context but it did not help improve the students' ability to recall information. This is in line with Merchant et.al (2012) and Rutten et.al (2012) who indicated an advanced understanding of information with the use of virtual simulations.

Though the simulation only had influence at a lower level of understanding to recognize information the students who participated in that section of the class identified benefits to the use of the simulation. The students expressed agreement that the simulation helped them to become more interested in the content as compared to when it only presented with traditional means. Students also felt there were benefits to using the simulation in helping them better understand the material.

Further analysis and study will be conducted. Comparisons of student overall class performance and how it relates to their performance on the assessment will be mapped. Students were also asked to record the approximate time they were in the simulation to examine the claim that more time within the virtual environment does not correlate to greater knowledge gain (Merchant et.al, 2014). The perception questions will also be aligned with responses on the assessment to see if there are any correlations to prior use of games and performance, prior use of games with level of acceptance to the technology, and other trends. Studies have also indicated that the use of a user controlled simulated environment allows for the enhancement of self-efficacy (Makransky and Petersen, 2019) so comparison of students perceptions based on their ability to learn from the environment and their performance on the assessment will also be examined. Additionally, the simulation is also be adapted to an immersive headset. One more iteration of the class where students have the ability to utilize the simulation on the VR headset will be conducted. The students will complete the same assessment and then all three groups will be compared to identify if there is any actual or perceived benefit of utilizing either of the technological interventions. 


\section{References}

Frein, L. and Ott, M. (2015) A literature review on immersive virtual reality in education: State of the art and perspectives, eLearning and Software for Education (eLSE), Bucharest, Romania.

Hilfert, T., Teizer, J., Konig, M. (2016) First Person Virtual Reality for Evaluation and Learning of Construction Site Safety, $33^{\text {rd }}$ International Symposium on Automation and Robotics in Construction (ISARC 2016).

Jaiswal, N., Ray, W., Slobounov, S. (2010) Encoding of visual-spatial information in working memory requires more cerebral efforts than retrieval: evidence from EEG and virtual reality study. Brain Research 1374, 80-89.

Makransky, G. and Petersen, G. B. (2019). Investigating the process of learning with desktop virtual reality: A structural equation modeling approach, Computers \& Education, 134(2019), 15-30.

Maghool, S.A.H., Moenini, S.H., and Arefazar, Y. (2018). An Educational Application Based on Virtual Reality Technology for Learning Architectural Details: Challenges and Benefits, ArchNet: International Journal of Architectural Research, Vol. 12, No. 3, 246-272.

Merchant, Z., Goetz, E.T., Keeney-Kennicutt, W., Kwok, O., Cifuentes, L., and Davis T.J. (2012). The learner characteristics, features of desktop 3D virtual reality environments and college chemistry instruction: A structural equation modeling analysis, Computers \& Education, 59(2012), 551-568.

Merchant, Z., Goetz, E.T., Cifuentes, L., Keeney-Kennicutt, W., and Davis, T.J. (2014). Effectiveness of virtual reality-based instruction on students' learning outcomes in K-12 and higher education: A meta-analysis, Computers \& Education, 70(2014), 29-40.

Lin, Y., Chen, Y., Yien, H., Huang, C., and Su, Y. (2018) Integrated BIM, game engine and VR technologies for healthcare design: A case study in cancer hospital. Advanced Engineering Informatics, 36(2018): 130-145.

Lucas, J. (2018) Student Perceptions and Initial Response to use Virtual Reality for Construction Education, 54 $4^{\text {th }}$ ASC Annual International Conference, Minneapolis, MN April 17-21, 2018.

Lucas, J. (2020) Rapid Development of Virtual Reality Based Construction Sequence Simulations: A Case Study. Journal of Information Technology in Construction (ITcon). (Accepted in Press)

Pariafsai, F. (2016) Effectiveness of a Virtual Project-Based Simulation Game in Construction. International Journal of Scientific Research in Science, Engineering, and Technology, 2(5): 377-393.

Pedro, A., Le, Q.T., and Park, C.S. (2016) Framework for integrating safety into construction methods education through interactive virtual reality. Journal of Professional Issues of Engineering Education and Practice 142(2): 04015011.

Rutten, N., van Joolingen, W.R, van der Veen, J.T. (2012) The learning effects of computer simulations in science education. Computers and Education, 58(2012): 136-153.

Sala, N.M. (2016) Emerging Tools and Applications of Virtual Reality in Education, ed. Choi, D.H., Dailey-Herbert, A., and Estes, J.S. IGI Global, Hershey PA USA.

Sampaio, A., Ferreira, M., Rosario, D., Martins, O. (2010). 3D and VR models in Civil Engineering education: Construction, rehabilitation, and maintenance. Automation in Construction, 19(7): 819-828.

Winn, W., Windschitl, M., Fruland, R., and Lee, Y. (2002). When does immersion in a virtual environment help students construct understanding. Proc. of the International Conference of the Learning Sciences, ICLS, 497-503.

Youngblut, C. (1998) Educational uses of virtual reality technology. Tech. rep., DTIC Document. 